\title{
Advancing climate adaptation and risk management. New insights, concepts and approaches: what have we learned from the SREX and the AR5 processes?
}

\author{
Joern Birkmann ${ }^{1} \cdot$ Reinhard Mechler ${ }^{2}$
}

Received: 19 February 2015 / Accepted: 18 September 2015 / Published online: 5 October 2015

(C) Springer Science+Business Media Dordrecht 2015

\section{Introduction and overview}

The IPCC Special Report on Managing the Risk of Extreme Events to Advance Climate Change Adaptation (SREX report; IPCC 2012) as well as the contribution of working group II to the IPCC fifth assessment report (IPCC 2014a, b; hereafter, WGII AR5) have been important milestones marking the confluence of the fields of climate adaptation and risk management. Both reports underscore the importance of taking a risk perspective in order to assess the different dimensions of threats linked to climate change. In addition, the enhanced linkages between disaster risk management and climate change adaptation also demonstrate that climate change is contributing to increasing climate extremes and significantly exacerbating adverse impacts. At the same time, the SREX report and the WGII AR5 point out that many non-climatic factors are fundamentally shaping the vulnerability of societies exposed to climate change related hazards; some of these issues deserve additional attention and scholarly debate. This special issue reflects on core issues as well as gaps and open questions identified in both reports, such as: (i) how to define and differentiate extreme events and extreme impacts, (ii) what is the role of vulnerability for assessments of climate-related risk, (iii) how do different types of urbanization influence risks in the context of climate change, and (iv) how to develop scenarios for vulnerability and risk in order to complement existing climate change scenarios. In addition the role of risk financing instruments generally, and micro-insurance in particular as tools for complementing risk reduction and adaptation as part of comprehensive risk management is explored.

This article is part of a Special Issue on "Advancing Climate Change Adaptation and Risk Management" edited by Joern Birkmann and Reinhard Mechler.

Joern Birkmann

joern.birkmann@ireus.uni-stuttgart.de

Reinhard Mechler

mechler@iiasa.ac.at

1 Institute of Spatial and Regional Planning, University of Stuttgart, Stuttgart, Germany

2 International Institute for Applied System Analysis (IIASA), Laxenburg, Austria 
Overall, the items discussed in the special issue are also linked to the current discussion regarding the new international agenda for Disaster Risk Reduction that has just been reinvigorated and updated as the Sendai Framework of Action (UN/ISDR 2015) and the Post-Kyoto Protocol process that particularly will be addressed in the Paris Meeting at the end of 2015. The Sendai Framework for Disaster Risk Reduction 2015-2030 (short Sendai Framework) defines future priorities and needs for disaster risk reduction. It was adopted at the Third World Conference for Disaster Risk Reduction in March 2015 in Sendai (Japan) by more than 180 countries. Thus, the contributions of the special issue provide timely input to the ongoing policy processes, such as the further development of the UNFCCC's Loss and Damage programme, the development of National Adaptation Plans (NAPAs) by Least Developed Countries (LDCs) as well as adaptation policy in developed countries and the implementation of the Sendai Framework for Action.

This special issue focuses on the advancement of climate change adaptation and risk management particularly in terms of the improved consideration of the linkages between climate change and extreme events as well as vulnerability and different development pathways. All papers revisit key findings of the IPCC-SREX report and the AR5 and address the issue of challenges of adapting to climate change and managing extreme events. In this regard, the different contributions reveal present opportunities and constraints of climate change adaptation and risk management through different perspectives, which we summarize here.

\section{Extreme events}

To start off the discussion on assessing and managing climate extremes, the paper by Nicholls and Seneviratne (2013) provides expert perspective on the definition of extreme events and outlines how assessments of changes in extremes have progressed over time after the 4th assessment report up to the SREX report. The comparison, which focuses on global-scale changes in extremes, exhibits that many of the assessments of changes in extremes are essentially identical or in partial agreement, and that differences are mostly due to changes in guidance for using IPCC uncertainty language, which was revised mid- way through the SREX process. Nicholls and Seneviratne explore the level of confidence in terms of how, for example, observed changes in tropical cyclones and droughts can be linked to climate change. As one finding, the paper suggests that increased consistency in the approaches between assessments would help to simplify future attempts to compare the assessed uncertainties associated with changes in extremes, although changes in the wording of such assessments also need to be considered.

\section{Vulnerability and disaster risk}

Moving from the physical to the social sciences, the contribution by Mechler and Bouwer (2014) examines the potential contribution of climate change to the large observed increases in economic losses, and specifically the role of economic vulnerability in shaping risk from climate extremes. Although anthropogenic climate change is modifying weather and climate extremes (as outlined in the paper by Nicholls and Seneviratne 2013), it is still an important question whether and how climate change leads to changes in people affected and capital put at risk. One key gap addressed in the 
analysis is the incomplete consideration of economic vulnerability to natural hazards, defined as the propensity to incur losses in a hazardous event. Since various studies have almost completely focused on adjusting losses for exposure changes, the authors examine also whether in many regions losses actually increase or decline due to decreases in vulnerability. The paper presents a novel methodology to empirically measure and project economic vulnerability, and provides context by way of a modeling case study of observed and projected losses from riverine flooding in Bangladesh, a country where there is evidence that vulnerability to loss of life and economic vulnerability have been substantially reduced, to some extent owing to international support received.

\section{Urbanization, climate change and vulnerability}

Climate change and urbanization are two global megatrends that heavily modify risks from extreme events at present and may do so even more in the future. While many publications and scholars consider urbanization as a driver of risk, Garschagen and Romero-Lankao (2013) in their contribution explore the relationship between these two mega-trends. Using international data on urbanization processes and vulnerability and also considering the WorldRiskIndex methodology, the authors conclude that urbanization does not necessarily increase vulnerability. The authors conduct a global analysis of urbanization patterns and processes in various countries and regions and provide a new innovative taxonomy on vulnerability and adaptive capacity in different urbanization contexts. The authors explore whether and how in various countries urbanization and economic transformation modify vulnerability patterns and adaptive capacities of people in urban areas to deal with extreme events. Their findings call for a more nuanced perspective on urbanization and its role as a driver of risk versus a driver of resilience.

\section{Scenarios for vulnerability and exposure}

To date most scientific assessments as well as policy endeavours for adaptation and risk reduction in the context of climate change make use of scenarios of climatic change. However scenarios for societal development, particularly in terms of different dimensions of exposure, vulnerability and adaptive capacity are often lacking and are an emerging field of research. Based on this observation, Birkmann et al. (2013) explore whether and how scenario tools of the global modeling community can also be used and tested for the context of risk and vulnerability reduction in the framework of climate change. In addition, the authors juxtapose global quantitative scenario approaches that focus on different future exposure pathways with a local participatory scenario approach that examines different futures of Jakarta in terms of a more adaptive versus non-adaptive development pathway. In this regard, the paper explores new methodological ground in terms of applying different scenario techniques in the field of vulnerability and risk assessment to climate influenced hazards. Therewith, the paper fosters a better understanding of the opportunities and constraints that vulnerability scenarios at different spatial scales contain as an analytic and normative tool supporting the identification of future risk hotspots and risk profiles. 


\section{Sea-level rise: resilience and shifts in agro-ecosystems}

Whether sea-level rise is an extreme event - or not - is still controversial; what is evident, however, is that sea-level rise is a major challenge for various coastal regions and might lead to extreme negative impacts that are in the core focus of risk reduction in the context of climate change. As in most deltas around the world, the population and infrastructure of the Mekong delta (MD) is highly exposed and vulnerable to the effects of sea level rise. The creeping hazard of salinity intrusion in surface and groundwater systems poses a particularly severe challenge to coastal agricultural communities and ecosystems. In this regard Renaud et al. (2014) explore how people cope and adapt to increasing salinity intrusion. The authors examine how different farming communities and agro-ecosystems cope and adapt to increasing salinity. In addition, the paper examines the role of different intervention measures implemented to deal with salinity intrusion and coastal hazards, such as dyke systems. Overall, the paper underscores that up to now business-as-usual policies are often favored over alternative approaches by farmers and policy makers.

\section{Financial instruments for disaster risk management and adaptation}

There is great interest in climate research, policy and practice regarding the role of risk financing instruments for disaster risk management and climate change adaptation. While insurance and other instruments have seen wide implementation for dealing with extreme events, including climate-related ones, there are important knowledge gaps. Not enough is known regarding the potential of risk financing instruments to incentivize risk reduction and broadly build resilience. Moreover, the role of such instruments in a changing climate needs more attention. The discussion by Linnerooth-Bayer and Hochrainer-Stigler (2014) provides perspective on this set of insurance-related measures, particularly regarding their role in developing countries with less developed insurance markets and an increased up-take for non-traditional pre-disaster instruments, such as index-based insurance. The discussion lays out the benefits of financial instruments, including the provision of post-disaster finances for recovery and pre-disaster security, which have important implications for climate adaptation and poverty reduction. Since these benefits are associated with costs (due to implementation and premium payments), the risks, challenges, and future prospects of risk financing in developing countries deserve careful attention. As its key contribution, the paper suggests a comprehensive risk management approach, which targets risk reduction and risk financing for different (so-called) layers of risk, and proposes to consider a layer for supporting communities and countries that possibly face limits to adaptation.

\section{Microinsurance for coping and adaptation}

Over the years, microinsurance, i.e., insurance catering to low-income households, has seen wide implementation, while the focus has been on health and life risks. Less is known about the potential of microinsurance for helping low-income households to cope with extreme weather, particularly in a well-defined case study context. Providing insight from a case study conducted in the Caribbean, Lashley and Warner (2013) examine the set of financial measures employed by households for coping with and adapting to weather extremes, and whether there 
is scope for financial risk management tools that could complement current asset-depleting approaches. Based on a survey of 1059 low-income persons working in agriculture and tourism in Belize, Grenada, Jamaica and St. Lucia, the paper explores and evaluates different measures used by respondents to manage the effects of extreme weather events. The dominant response and management approaches, such as borrowing and government assistance, are examined and the demand for weather-related micro-insurance is discussed. Overall, the analysis calls for more comprehensive risk management approaches that also consider the level of vulnerability and coping capacities of communities to extreme events.

\section{Transformative change in climate change adaptation}

Resilience building, adaptation and transformation are core terms of the newer discourse on how to classify different levels of change in the light of global environmental and socioeconomic change that also manifests itself in specific local settings. The final, conceptual paper by Pelling et al. (2014) addresses three core questions. First, it examines what relationship exists between transformation, incremental adaptation, stability and resilience within a theoretical perspective. Secondly, the paper explores how and where transformation might emerge and spread through adaptation processes. This allows the authors to also provide concrete examples on how to differentiate incremental change from deeper transformation processes. Thirdly, the author team focuses on the question of the ways in which transformation provokes changes in approaches to adaptation. Even though the paper has a strong sympathy for promoting the concept of transformation, the authors also raise critical issues. In this regard, the concept of transformation is further deconstructed within the context of decision-making. Moreover, the authors explore how the abstract concept of transformation can be operationalized with concrete examples on the ground and for the day-to-day reality of people exposed to extreme events. Pelling et al. argue that the concept of transformation can be an important lens to explore the hidden preferences through adaptation choices and can explore challenges to address and change dominant power relations.

\section{References}

Birkmann J, Cutter SL, Rothman DS, Welle T, Garschagen M, van Ruijven B, O’Neill B, Preston BL, Kienberger S, Cardona OD, Siagian T, Hidayati D, Setiadi N, Binder CR, Hughes B, Pulwarty R (2013) Scenarios for vulnerability: opportunities and constraints in the context of climate change and disaster risk. Clim Chang. doi:10.1007/s10584-013-0913-2, online first

Garschagen M, Romero-Lankao P (2013) Exploring the relationships between urbanization trends and climate change vulnerability. Clim Chang. doi:10.1007/s10584-013-0812-6, online first

IPCC (2012) Managing the risks of extreme events and disasters to advance climate change adaptation. In: Field CB, Barros V, Stocker TF, Qin D, Dokken DJ, Ebi KL, Mastrandrea MD, Mach KJ, Plattner G-K, Allen SK, Tignor M, Midgley PM (eds) A special report of working groups I and II of the intergovernmental panel on climate change. Cambridge University Press, Cambridge

IPCC (2014a) Climate change 2014: impacts, adaptation, and vulnerability. Part A: global and sectoral aspects. In: Field CB, Barros VR, Dokken DJ, Mach KJ, Mastrandrea MD, Bilir TE, Chatterjee M, Ebi KL, Estrada YO, Genova RC, Girma B, Kissel ES, Levy AN, MacCracken S, Mastrandrea PR, White LL (eds) Contribution of working group II to the fifth assessment report of the intergovernmental panel on climate change. Cambridge University Press, Cambridge

IPCC (2014b) Climate change 2014: impacts, adaptation, and vulnerability. Part B: regional aspects. In: Barros VR, Field CB, Dokken DJ, Mastrandrea MD, Mach KJ, Bilir TE, Chatterjee M, Ebi 
KL, Estrada YO, Genova RC, Girma B, Kissel ES, Levy AN, MacCracken S, Mastrandrea PR, White LL (eds) Contribution of working group II to the fifth assessment report of the intergovernmental panel on climate change. Cambridge University Press, Cambridge, 688 pp

Lashley J, Warner K (2013) Evidence of demand for microinsurance for coping and adaptation to weather extremes in the Caribbean. Clim Chang. doi:10.1007/s10584-013-0922-1, online first

Linnerooth-Bayer J, Hochrainer-Stigler S (2014) Financial instruments for disaster risk management and climate change adaptation. Clim Chang. doi:10.1007/s10584-013-1035-6, online first

Mechler R, Bouwer LM (2014) Understanding trends and projections of disaster losses and climate change: is vulnerability the missing link? Clim Chang. doi:10.1007/s10584-014-1141-0, online first

Nicholls N, Seneviratne S (2013) Comparing IPCC assessments: how do the AR4 and SREX assessments of changes in extremes differ? Clim Chang. doi:10.1007/s10584-013-0818-0, online first

Pelling M, O’Brien K, Matyas D (2014) Adaptation and transformation. Clim Chang. doi:10.1007/s10584-0141303-0, online first

Renaud FG, Le Huong TT, Lindener C, Guong VT, Sebesvari Z (2014) Resilience and shifts in agro-ecosystems facing increasing sea-level rise and salinity intrusion in Ben Tre Province, Mekong Delta. Clim Chang. doi: 10.1007/s10584-014-1113-4, online first

UN/ISDR (United Nations - International Strategy for Disaster Reduction) (2015) Sendai Framework for disaster risk reduction 2015-2030, outcome of the third world conference on disaster risk reduction [A/CONF.224/ CRP.1], 14-18 March 2015, Sendai, Japan 